\title{
Assessing vulnerability of forests to climate change in South Korea
}

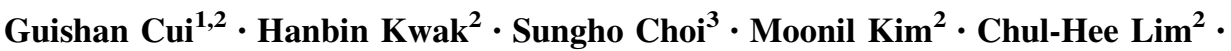 \\ Woo-Kyun Lee ${ }^{2} \cdot$ Joon-Soon Kim ${ }^{4} \cdot$ Yeora Chae $^{5}$
}

Received: 4 October 2014/Accepted: 11 June 2015/Published online: 26 December 2015

(C) The Author(s) 2015. This article is published with open access at Springerlink.com

\begin{abstract}
This study demonstrated a framework to assess vulnerability of forests to climate change. We focused on how alterations of temperature and precipitation might affect forest type distributions and carbon-related functions. In particular, our framework considered three sectors of forest type distribution, net primary production, and soil carbon storage. Future projections were derived from mechanistic models for South Korean forests under the A1B scenarios of the intergovernmental panel on climate change. Forest type distributions were simulated by the Hydrological and thermal analogy group model, while the MAPSS and CENTURY1 models estimated forest carbon
\end{abstract}

Project funding: This study was funded by the Korea Ministry of Environment as "The Climate Change Correspondence R\&D Project (RE 201206045)" and "Climate Change Correspondence Program" (Project Number: 2014001310008).

The online version is available at http://www.springerlink.com

Corresponding editor: Zhu Hong

Woo-Kyun Lee

leewk@korea.ac.kr

1 Department of Geography, Yanbian University, Yanji 133002, People's Republic of China

2 Department of Environmental Science and Ecological Engineering, Korea University, Anam-dong 5ga, Sungbuk-gu, Seoul 136-713, Republic of Korea

3 Department of Earth and Environment, Boston University, Boston, MA 02215, USA

4 College of Forest and Environmental Science, Kangwon National University, Chunchon 200-701, Republic of Korea

5 Division of Adaptation Research, Korea Environment Institute, 8F 11F, Bldg B, 370 Sicheong-daero, Sejong 30147, Republic of Korea flux/storage. We quantified normalized vulnerability indices for each sector. Our results indicate that the overall vulnerability of forest type distribution is greater in the west central regions and southeastern inlands. The vulnerabilities of carbon flux/storage show that net primary production of South Korean forests is relatively less susceptible to climate change, but a highly vulnerable area of soil carbon storage mainly spreads from the west central to the south east region. The spatio-temporal vulnerability map with a synoptic overview from this study might be useful for policy makers in preparing adaptive measures and identifying management priorities.

Keywords Vulnerability · Forest - Climate change . Forest assessment

\section{Introduction}

Climate change is one of the most widely recognized global challenges adversely affecting local and regional environments (Joshi et al. 2012). Predicting its future impacts on forest ecosystems is of interest to research scientists, policy makers, and the public. Approximately $64 \%$ of South Korean terrain is covered by forests that have partially offset $\mathrm{CO}_{2}$ emissions from land-use changes and fossil fuel burning (Korea Forest Service 2011). Although forest ecosystems are important carbon sinks, inverse fluxes are expected (i.e., forests acting as carbon sources) when environmental conditions are not favorable for photosynthesis or when autotrophic/heterotrophic respiration escalates (Wang et al. 2004, 2008). Moreover, a significant amount of $\mathrm{CO}_{2}$ would be released to the atmosphere due to the loss of forests resulting from natural/ anthropogenic disturbances (Evrendilek et al. 2007). An 
increase in temperature, for example, could extend the growing season and enhance net primary production (NPP) (Myneni et al. 1997), but might also decrease soil carbon storage (SCS) by increasing microbial activities (Kirschbaum 1995). Forest type distribution is determined primarily by temperature and water availability (Prentice et al. 1992).

Model-based impact assessments have been conducted on forest type distributions and carbon-related functions across different regions (Zhang et al. 2011; Zhu et al. 2006). Changes in plant functional types in California were simulated using the MAPSS-CENTURY1 (MC1) model (Lenihan et al. 2008). Their study demonstrated that rising average temperatures would extend growth periods of plants and increase productivity of evergreen hardwoods while causing a reduction in productivity of evergreen coniferous forests. In China, the Carbon Exchange between Vegetation, Soil, and Atmosphere (CEVSA) model was used to predict that mixed forests and deciduous broadleaf forest zones would migrate northward, whereas shrub zones in southern China would expand laterally due to climate change (Yu et al. 2006). Yu et al. (2008) used CEVSA, a process-based model for ecosystems, to analyze impact for potential forest distribution and ecosystem function based on climate change. Northern areas were predicted to have higher ecosystem vulnerability to climate change than southern areas, and western areas were more vulnerable than eastern areas in China. Analysis results for future ecosystems predicted that natural ecosystem vulnerability would increase nationwide because of the impact of the A2 scenario and spatial distribution would be similar to that under present climate conditions. Based on this research, Yu et al. (2008) proposed a method which is efficient for conducting relative assessment for ecosystems, and which leads to understanding of ecosystem conditions and stability.

In Korea, the CEVSA (Lee et al. 2007a) and MC1 (Choi et al. 2011a) models have been applied for predicting potential vegetation distributions and carbon-related functions under future climate scenarios. Since the forest type distribution of South Korea is determined by relatively complex terrain and climatic conditions at local and regional scales, the thermal analogy groups (TAG) model (Choi et al. 2010) and hydrological and thermal analogy group (HyTAG) model (Choi et al. 2011b) are also recommended for climate change impact assessments of forest ecosystems (Choi et al. 2011a; Lee et al. 2010; Lee et al. 2011; Byun et al. 2012).

Lee et al. (2011) estimated forest vulnerability based on A2 and B1 climate change scenarios using the HyTAG and MC1 model. Based on scenario A2, forests located in subalpine and cold temperate zones will decreased in area over time and will be distributed in the Kang-Won-Do area and warm temperate forest will shift northward. Although subalpine forest will decline and evergreen forest located in the warm temperate zone will increase over time based on scenario B1, no obvious changes for forest types were predicted for the near and distant future. Lee et al. (2011) compared scenarios between $\mathrm{A} 2$ and $\mathrm{B} 1$ and estimated that $\mathrm{A} 2$ produced higher growth rates for temperature than $\mathrm{B} 1$. Based on A2, sensitivity of forest ecosystem will be higher and the area of adaptability will decline, resulting in an increase in the extent of vulnerable area.

Byun et al. (2012) used the HyTAG, MC1 model and social environmental indices to analyze forest ecosystem vulnerability distinguish sensitivity, exposure and adaptability in South Korea. They predicted that forests located in northeastern and southern South Korea will be highly vulnerable to climate change. However, Jeju Island and southwestern forests would have very low vulnerability. Vulnerability would increase with no change in forest distribution but northeastern forests that are relatively vulnerable will decline in future. Byun et al. (2012) predicted that forest ecosystem vulnerability will increase nationwide, and among their indices of vulnerability assessment, social environmental indices were predicted to have the greatest impact.

The impacts of climate change have been satisfactorily investigated, and sophisticated modeling is now feasible with classified monitoring and data handling techniques. However, we are still missing a framework that quantifies and unifies numerous climate change impacts on forests (Lindner et al. 2010). Although climate research has significantly progressed in a variety of individual sectors, a synoptic overview remains elusive and it is often difficult for policy makers or the public to interpret (Arvai et al. 2006). Therefore, this study suggests an approach for integrating model-based impact assessments, particularly focusing on how climate change may affect forest type distributions and carbon-related functions in South Korean forests. We selected three sectors for our framework in which model-based assessments are available for South Korea: (a) forest type distribution, (b) NPP, and (c) SCS.

Our objectives were to produce spatially stratified and normalized vulnerability indices for the three sectors, and to develop a summarized overview of vulnerability that can support climate change policy-makers in South Korea. The study area and climate data are given in "Study area" section and "Climate data" section; Concepts and definitions for the vulnerability assessment used in this study are provided in "Forest type distribution and carbon-related functions (NPP and SCS)" section; and the selected models for South Korean forests are also briefly described in "Vulnerability of forest type distribution and carbon-related functions (NPP and SCS)" section. In addition, one vulnerability criterion for forest type distribution and other 
criteria for carbon-related functions are explained in "Temporal and spatial transitions of vulnerabilities for each sector" section. We provide results and discussions in "Discussion" section and "Conclusion" section, respectively. Lastly, Sect. 6 presents our conclusions.

\section{Method and materials}

\section{Study area}

The study area included the entirety of South Korea $\left(33^{\circ} 09^{\prime}-38^{\circ} 45^{\prime} \mathrm{N}\right.$ latitude and $124^{\circ} 54^{\prime}-131^{\circ} 06^{\prime} \mathrm{E}$ longitude). The spatial resolution was set at approximately $1 \mathrm{~km}$ for input raster datasets and final results. Mountainous areas on the eastern part of South Korea have dense forests, whereas the western area is composed of flatland and highly populated cities (Fig. 1).

South Korea has the following nine administrative provinces, viz. Gyeonggi, Gangwon, Chungbuk, Chungnam, Jeonbuk, Jeonnam, Gyeongbuk, Gyeongnam and Jeju (Fig. 1b). Gyeonggi province is highly populated and contiguous to Seoul, the capital city of South Korea.

(a)
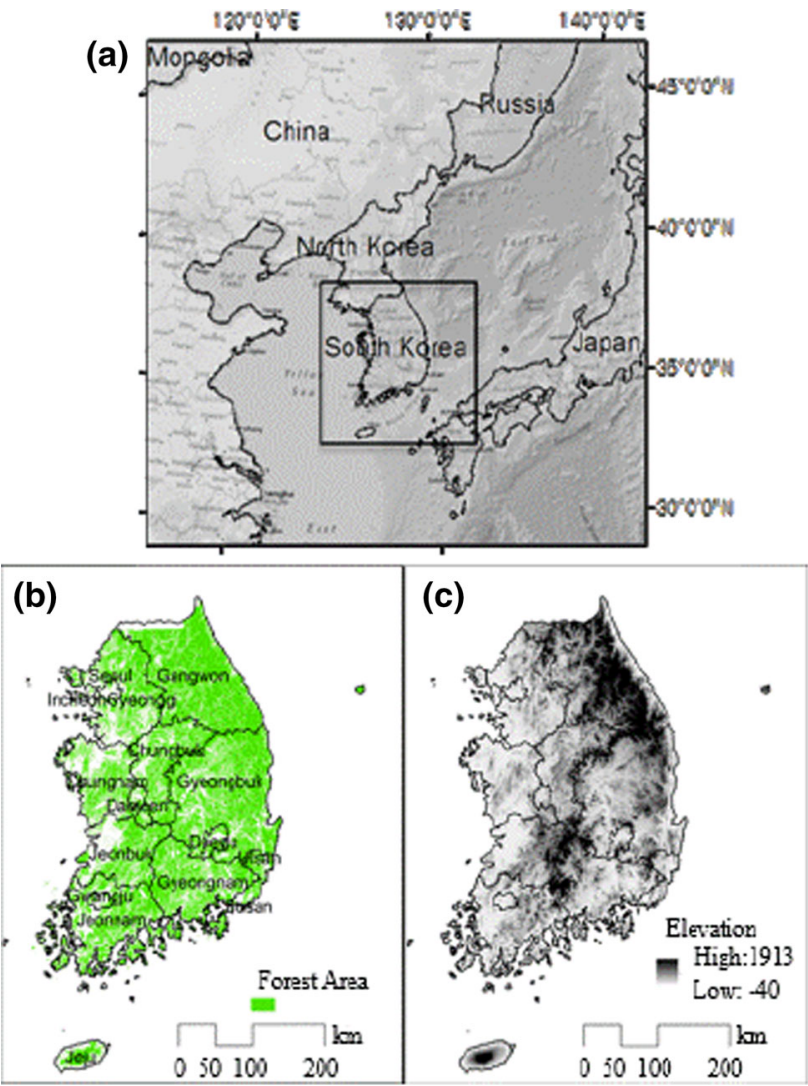

Fig. 1 a The study area includes the entirety of South Korea with b $65 \%$ of forested lands and c relatively complex topography at local and regional scales
Gangwon province, located in eastern South Korea, has mountainous topography and substantial forest diversity. Lastly, there are the six metropolitan cities

\section{Climate data}

To assess vulnerability, monthly mean temperature, minimum temperature, precipitation, and mean relative humidity were used in this study. Historical climate data were obtained from 75 climate stations by the Korea Meteorological Administration, and we interpolated point datasets using inverse distance squared weighting (IDSW) and Kriging (Lee et al. 2007a). The altitudinal lapse rate of temperature was calculated using Eq. (1) as suggested by Yun et al. (2002). Precipitation was also rectified using elevation effects, as in Eqs. (2) and (3) (Smith 2008).

$T=T_{i}+E \times|\tau|$

$P=P_{i} \times 1.74^{E / 1000}$

$P=P_{i} \times 0.54^{E / 1000}$

where, $T_{i}$ and $P_{i}$ refer to air temperature and precipitation $(i=$ day), respectively, before correcting for elevation $(E)$ effects. $T$ corresponds to air temperature at an elevation given the altitudinal lapse rate $(\tau)$.

According to Yun et al. (2001), the daily $\tau$ for the mean temperature is $|\tau|=0.00688+0.0016 \cos 0.0172(i-60)$ and the daily $\tau$ for the minimum temperature is $|\tau|=0.00695+0.0013 \cos 0.0172(i-30)$. Precipitation $(P)$ at a given elevation was estimated by Eq. 2 for the cold season from October to April, and by Eq. 3 for the warm season from May to September. Future climate datasets with a resolution of $27 \mathrm{~km}$, were provided by the National Institute of Meteorological Research (NIMR) in South Korea, and also consisted of monthly temperature, monthly minimum temperature, and monthly mean relative humidity. The climate change scenario used in this study was A1B (Nakicenovic et al. 2000) of the intergovernmental panel on climate change (IPCC). Future climate data were simulated by the Fifth-Generation National Center for Atmospheric Research (NCAR)/Penn State Mesoscale Model (MM5) with ECHO-G initial boundary conditions from the Max Planck Institute in Germany (Min et al. 2006; Cha and Lee 2009).

\section{Vulnerability assessment, concepts and definitions}

A number of definitions for vulnerability of forests are documented by major scientific groups and policy-makers. In this study, we used the concept of vulnerability that combines the two criteria of sensitivity and adaptation capacity, following Lindner et al. (2010), McCarthy (2001), Watson and Albritton (2001) and Füssel and Klein 
(2006). The vulnerability in this study describes, in particular, the degree of alteration of forest type distributions and carbon-related functions (NPP and SCS) due to climate change. Our goal was to quantify climate change impacts on the three sectors (i.e., forest type distribution, NPP, and SCS) and to produce a synoptic overview for policy makers in South Korea (Fig. 2).

Vulnerability indices (VI) were calculated from the spatially stratified and normalized criteria of sensitivity (S), and adaptation capacity (A) for each sector (Eq. 4). The criteria can be numerically expressed by indicators which were computed using the suggested models (HyTAG and MC1) for South Korean forests (see "Vulnerability of forest type distribution and carbon-related functions (NPP and SCS)" section).

$V I=f(S, A)=S-A$

where, $V I$ is the vulnerability index. $S$ refers to sensitivity, and $A$ corresponds to adaptation capacity. Our definition of adaptation capacity was solely based on the ability to adjust in forest ecosystems, that is, autonomous adaptation (Füssel and Klein 2006). The commonly used adaptation capacity by human activity (e.g., forest management) was beyond the scope of this study. The normalized criteria were assumed to be independent of each other, thus we

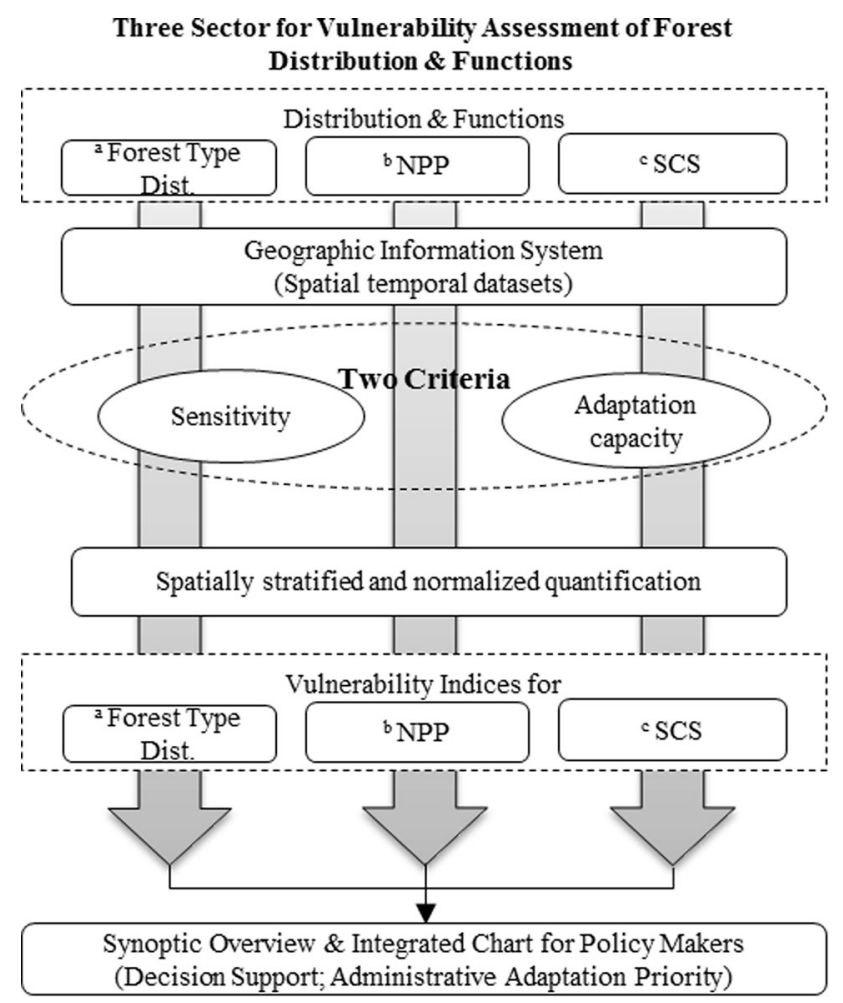

Fig. 2 Scheme of the climate change vulnerability assessment of forests in the study. ${ }^{\text {a }}$ orest type dist. is forest type distribution, ${ }^{b} \mathrm{NPP}$ is net primary production, ${ }^{\mathrm{c}} \mathrm{SCS}$ is Soil carbon storage combined two criteria (sensitivity, adaptation capacity) into the vulnerability index for each sector. Specific definitions and assumptions for each sector and criterion are given in "Temporal and spatial transitions of vulnerabilities for each sector" section. The criteria were numerically expressed using indicators which resulted from model simulation (HyTAG and MC1). Specific methods of calculation are described in "Temporal and spatial transitions of vulnerabilities for each sector" section. The three sectors were assumed to be independent. The vulnerability indices for each sector were spatially rectified and normalized to facilitate the synoptic overview. This might be useful to compare vulnerabilities for each sector across administrative districts. In turn, our framework would support the decision-making (priority) for adaptive measures in response to climate change. However, the assumption of independence of sectors could be relaxed (e.g., changes in forest type could alter carbon-related functions). The limitations of our premise are discussed in "Conclusion" section.

\section{Selected models for simulation of forest type distribution and NPP/SCS}

As stated in "Forest type distribution and carbon-related functions (NPP and SCS)" Section, our framework particularly takes into account the three sectors of forest type distribution and carbon related functions (NPP, SCS). Future projections were derived from the suggested models for South Korean forests. Forest type distribution was simulated using the HyTAG model, whereas the MC1 model estimated forest carbon flux/storage.

\section{Model for forest type distribution}

Theoretically, dynamic global vegetation models (DGVMs) are spatial-scale independent and are applicable to both regional and global studies. However, DGVMs cannot provide reliable simulations of forest type distributions in South Korea due to relatively complex terrain features and environmental conditions (Lee et al. 2007a; Choi et al. 2011a; Kim et al. 2009; Kim and Lee 2006). To alleviate this limitation, Choi et al. (2011b) recommended the HyTAG model, which uses Korea-specific plant functional types (PFTs) based on hydrological and thermal indices, such as the precipitation effectiveness index (PEI), warmth index (WI), and minimum temperature of the coldest month index (MTCI). The PEI of Thornthwaite (1948) is a measure of the long-range effectiveness of precipitation in promoting plant growth at a given location. WI represents the effective heat for plants throughout a year and MTCI corresponds to the cold resistance of trees (Kira 1948; Neilson 1995). Using these parameters, the 
HyTAG model satisfactorily simulates potential responses of forest type distributions to climate change in South Korea (Choi et al. 2011b).

Given the optimal habitat ranges of PEI, WI, and MTCI for major tree species in South Korea, the HyTAG model provides a baseline estimate of forest type distribution. In this study, we used the actual forest distribution and historical climate data. The statistical hierarchical clustering module in SAS v9.2 (SAS 2009) determined eight PFTs in HyTAG model simulations. Changes in climate (i.e., temperature and precipitation) may alter spatial distributions of PEI, WI, and MTCI, and thus different PFTs would be assigned to the places where those indices are out of optimal habitat ranges (Choi et al. 2011b). In this study, we predicted future changes in potential forest type distributions using the HyTAG model. The time scale was set at 10 -years and the simulation was performed using a 10-year average of future climatic data.

\section{Model for carbon-related functions (NPP and SCS)}

From the many measures of carbon-related functions, we selected NPP and SCS. Not all carbon absorbed by forests is converted into biomass, and $\sim 50 \%$ is respired to the atmosphere (i.e., autotrophic respiration). The increase of forest biomass is related to net accumulation of carbon, that is, NPP. Some of the fixed biomass through the NPP flux (e.g., SCS) is consumed by bacteria and fungi, and is known as heterotrophic respiration (Rh). The difference between NPP and Rh refers to net ecosystem production (NEP) (Schulze et al. 2000). Since there were no suggested models for carbon-related functions in South Korea, we selected the MC1 model, a DGVM which can simulate carbon flux and storage (Bachelet et al. 2001). The biogeochemistry module of the MC1 model is comprised of a modified CENTURY model (Parton 1996), which uses monthly climate data to predict forest growth and organic matter decomposition (Lenihan et al. 2008). Some global parameters of the MC1 model may not be suitable for South Korean forests, so we prepared Korea-specific parameters where possible. Historical climate data were used to estimate the baseline distribution of NPP and SCS in South Korea. Then, similar to the forest type distributions (Sect. 3.2.1), future NPP and SCS were simulated for each decade.

\section{Criteria and indicators for vulnerability assessments}

As documented in many studies, a number of models account for various measures assessing forests vulnerability. In this study we computed "relative" criteria that are spatially stratified and normalized. For each indicator $(j)$, we simply explored the maximum $\left(A_{\max , n, j}\right)$ and minimum
$\left(A_{\text {min, } n, j}\right)$ modeled results given the entirety of the pixel values (total number $=n$ ) in South Korea. Normalized values $\left(R_{\text {normalized }} i, j\right)$ were then generated for each pixel (i). Based on the concepts and premises in "Forest type distribution and carbon-related functions (NPP and SCS)" section, we independently defined criteria associated with sensitivity and adaptation capacity, and these criteria were combined into vulnerability indices for each sector. Every single vulnerability index was also spatially normalized. These vulnerability indices were synopsized into an overview diagram that can support the climate change policymakers in South Korea (adaptation priorities by administrative boundaries). The following section outlines our specific definitions of criteria and indicators to compute vulnerability indices for each sector.

\section{Criteria for forest type distribution}

Potential forest type distributions from the 1970s to the 2090s were predicted as an indicator by the HyTAG model (Choi et al. 2011b). Here, we allocated the idle value for the exposure term (McCathy 2001) because the HyTAG model simulations already took into account the future climatic conditions (alterations of temperature and precipitation) under the A1B scenario of the IPCC.

Our definition of the sensitivity criterion for forest type distribution considered the total changes of predicted forest type over a pixel in a given time (1970-2090s). We simply investigated potential forest type changes as an indicator between the two consecutive periods (e.g., 1970 vs. 1980s, 1980 vs. 1990 s, etc.) of the HyTAG simulations. A comparison of forest types for the two simulations assigned the value zero for "no change" and one for "change" over the individual pixels. The sum of the changes (herein, "frequency of changing forest types") for individual pixels was then spatially stratified and normalized to calculate the sensitivity criterion over the entirety of South Korea (Yu et al. 2006; Choi et al. 2011a; Lee et al. 2007b) (Table 1). The larger frequency of changing forest types resulted in a greater sensitivity criterion for each pixel throughout the whole period.

Despite the protracted debates regarding the potential migration of tree species keeping pace with changing conditions (Pearson 2006), we assumed that the historically and currently valued forests remained susceptible to fragmentation and invasive tree species due to climate change. For instance, red pine (Pinus densiflora) is a native species of strong cultural importance in South Korea, and is also a domestic timber source. Potential habitats of red pine (in temperate mixed forests from HyTAG simulations) might be diminished in future climatic conditions. Based on a bioclimatic envelope concept (Pearson and Dawson 2003), we thus assumed that the HyTAG predictions could 
Table 1 Criteria and indicators to assess the climate change vulnerability index of forests

\begin{tabular}{llll}
\hline Sectors & & Criteria & Indicator \\
\hline Forest ecosystem & Forest type distribution & Sensitivity & Changing frequency \\
& & Adaptation capacity & Changing direction and degree \\
& NPP & Sensitivity & Accumulated deviation \\
& SCS & Adaptation capacity & The changing trends of NPP \\
& Sensitivity & Accumulated deviation \\
& Adaptation capacity & The changing trends of SCS \\
\hline
\end{tabular}

Net primary production (NPP); soil carbon storage (SCS)

provide a useful first approximation of the sensitivity term of forest type distribution.

The HyTAG model predicted a certain decline of habitats for subalpine, cool temperate, and temperate forests from the 1970s to the 2090s. Future temperature and precipitation under the A1B scenario might be favorable to subtropical and warm temperate forests. Here, our definition for the adaptation capacity term took into account the direction and degree of forest type changes over a pixel in a fixed period. The HyTAG simulations from the 1970s to the 2090s resulted in a decrease in of potential habitats for subalpine, cool temperate, and temperate forests, whereas future climate conditions (under the A1B scenario) in South Korea are favorable to sub-tropical and warm temperate forests. Thus, we assumed that the direction of forest type changes from subalpine to subtropical represent a negative response of forests to climate change in South Korea (i.e., less adaptation capacity). On the other hand, an opposite direction corresponded to the positive response. Building upon this direction term following Kong's (2005) approach, we also estimated the degree of forest type changes from comparisons of PFTs between the two consecutive periods of the HyTAG simulations. A larger negative value refers to an abrupt transition of PFTs in the negative direction over a pixel (i.e., less adaptation capacity). For example, we allocated -2 for a pixel with changes from cool temperate mixed forests to temperate mixed forests (difference of PFTs), whereas +5 was assigned for a pixel with changes from subtropical evergreen to cool temperate deciduous forests. We aggregated all of the estimates of the "direction and degree" of forest type changes for individual pixels from the 1970s to the 2090s. These aggregations were then spatially stratified and normalized to calculate the criterion for the adaptation capacity in South Korean forests (Table 1).

\section{Criteria for carbon-related functions (NPP and SCS)}

The MC1 model simulated the potential NPP and SCS as an indicator from the 1970 s to the 2090s over South
Korean forests (Choi et al. 2011a). Forests exchange carbon with the atmosphere based on photosynthesis and respiration, and thus NPP and SCS are the important properties in forest carbon cycles (see Sect. 3.2.2). Through the rapid and slow carbon redistributions (fluxes) at hourly to decadal scales (basic nature of forest ecosystems), carbon budgets are balanced over long periods of time (Houghton 2007).

Therefore, we also investigated the deviations of NPP and SCS from their long-term means over a fixed period (Eq. 5). We used the same procedure to estimate the vulnerability indices for both NPP and SCS, but these carbonrelated functions were separately examined in this section. The sensitivity term of forest carbon-related functions was assessed by the "accumulated deviation from the longterm mean" from the 1970s to the 2090s simulations of the MC1 (Eq. 6, Table 1). Greater dispersion (i.e., more accumulated deviations) of NPP or SCS in a fixed period represented more sensitivity for carbon-related functions. Here, the sensitivity estimates were also spatially stratified and normalized.

$\begin{aligned} Y_{i} & =\frac{\left|V_{i}-\bar{V}\right|}{\bar{V}} \\ D_{n} & =\frac{\sum_{i=1}^{j}\left|V_{i}-\bar{V}_{n}\right|}{\bar{V}_{n}}\end{aligned}$

where, $Y_{i}$ is the deviation from the mean of the forest function in the $i$ th period, $V_{i}$ is the value of forest carbonrelated functions in the $i$ th period, and $\bar{V}$ is the average of NPP or SCS from the 1970 s to the 2090s. $D_{n}$ denotes the accumulated deviations from the long-term mean in a fixed period (1970-2090s; $i$ th to $j$ th), and $n$ represents each pixel. We explored the trends of NPP or SCS deviations from the long-term means to explore the adaptation capacity criterion. Here, our concern was not the increasing or decreasing trends of carbon fluxes due to climate change, but the loss of resilience to perturbations over long time scales. The three simple examples of fluxes comprised of convergence, sine waves, and divergence were considered, and their fluctuations were assumed to be associated with 
external disturbances. A system with diverging fluxes might forfeit its resilient capacity for balance, which can be interpreted using a trend of its deviations from the longterm mean value (Lee et al. 2007a; Choi et al. 2011a; Lee et al. 2010; Lee et al. 2011; Yu et al. 2005, 2008).

Simple linear fitting curves were generated over the NPP and SCS deviations ( $Y=\alpha X+\beta$; where $X$ is the temporal period, $Y$ is the deviation (Eq. 5), $\alpha$ refers to the slope and $\beta$ corresponds to the intercept) (Table 1). The positive slope $\alpha$ (herein, "trend of deviations") represented "divergence" of the deviations and was interpreted as a lower adaptation capacity, assuming that greater adaptation capacity leads to a decreasing trend in deviations (negative slope $\alpha$ (Yu et al. 2006; Lee et al. 2007b): "convergence" of the deviations) for the entirety of South Korean forests.

\section{Results}

\section{Forest type distribution and carbon-related functions (NPP and SCS)}

In the baseline forest type distribution (from the 1970s to the 2000s), subalpine and cool temperate forests were distributed throughout the east-central and high mountainous areas, whereas temperate broadleaf forests were distributed throughout the lowlands of the southwest (Choi et al. 2011b). Temperate mixed forests were distributed between these two regions, and warm temperate forests were sparsely scattered throughout the southwest. Our models predicted that in the 2050s, the distribution of cool temperate forests and temperate forests will be diminished and warm temperate and subtropical forests will expand to the northeast. By the 2090s, cool temperate and temperate forests will occur only in high mountainous areas in eastcentral Korea. The other regions will be dominated by warm temperate and subtropical forests.

Potential NPP increased gradually from the 1970s to the 2090s, and its spatial variation over the entirety of South Korean forests was expected first to decrease by the 2010s and then increase until the 2080s (Choi et al. 2011b). The potential NPP of the southern and eastern coastal areas was relatively high, and that of the eastern coastal region was expected to increase as a result of climate change. The potential NPP of the eastern inlands was low. NPP was generally higher in warmer regions unless declines in precipitation are accompanied by temperature increases. The potential SCS was estimated to decline slightly from the 1970s to the 2090s. Between the 1970s and the 2030s, overall potential SCS was expected to be stable and begin to decrease gradually until the 2090s. Potential SCS in the southern and eastern coastal regions was relatively high and potential SCS of the southeast and southern regions was slightly low.

\section{Vulnerability of forest type distribution and carbon- related functions (NPP and SCS)}

Distinct spatial variations were found in the vulnerability index for forest type distribution, NPP and SCS over South Korea from the 1970s to the 2090s under the A1B scenario (Fig. 3; Tables 2, 3, 4).

In terms of forest type distribution, the central and southeastern regions were the most vulnerable to future climatic conditions, and other areas showed relatively lower vulnerability. The eastern mountainous regions were expected to be least vulnerable in change of forest type distribution. These results might be explained by the sensitivity and adaptation capacity of the regions. Overall, $<3 \%$ of South Korean forests would not experience a change in forest type, while the majority $(>80 \%)$ presented two to five degrees of total changing forest type throughout the simulation periods $(\max$ frequency $=11)$. Highly sensitive forest pixels $(7+$ frequency; $\sim 5 \%$ of the South Korean forests) were mainly located in the central and southeastern regions. The autonomous adaptation capacity of South Korean forests, in general, was low or very low ( $\sim 86 \%$ of total forested lands). Our simulations showed that $<2 \%$ of forests would face a zero or positive direction of forest type changes from the 1970s to the 2090s, whereas large type changes (e.g., -4 to -6 ) accounted for $\sim 17 \%$ of South Korean forests. Since the eastern mountainous regions would retain habitats for subalpine, cool temperate, and temperate forests, we expect a relatively high adaptation capacity of forest in these regions. Our combination of the sensitivity and adaptation capacity criteria produced the normalized vulnerability index map for the forest type distribution. This map depicts where the highly susceptible forest types are located (Fig. 3a).

While most $(\sim 86 \%)$ South Korean forests had low vulnerability indices for NPP, we expect only $\sim 46 \%$ of forests would be less susceptible to change in SCS in future climatic conditions. In terms of the NPP vulnerability index, the moderately to highly vulnerable regions (14\% of forests) were mainly located in the west-central regions and scattered in the eastern mountainous regions. There are two interpretations for this result. First, the degree of NPP changes over the west-central regions from the 1970s to the 2090s was amplified because of climate change. These regions were relatively stable in NPP until the 2010s, and thereafter began to lose capacity to balance NPP fluxes, that is, adaptation capacity declined over the years. Second, we found a relatively abrupt increase in NPP ( $>500 \mathrm{~g} \mathrm{C}$ $\mathrm{m}^{-2} \mathrm{a}^{-1}$ ) over the scattered eastern mountains until the 2030s ( $\sim 7 \%$ of South Korean forests). Even though NPP fluxes over the regions stabilized after this increment, a relatively larger sensitivity criterion was computed 


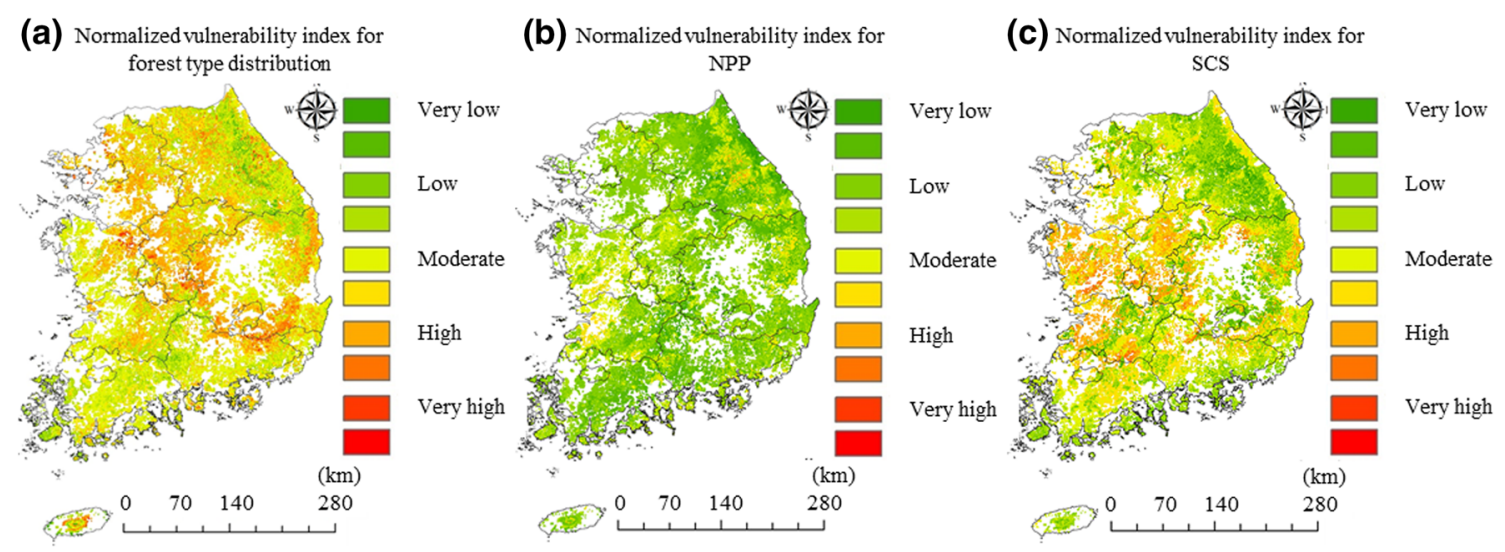

Fig. 3 Continuous field of the normalized vulnerability index for a forest type distribution, b NPP, and c SCS from the 1970s to the 2090s under the A1B scenario of the IPCC. The five classes in the

maps represent " $0.0 \leq$ Very low $<0.2$ ", " $0.2 \leq$ Low $<0.4$ ", " $0.4 \leq$ Moderate $<0.6$ ", " $0.6 \leq$ High $<0.8$ ", and " $0.8 \leq$ Very high $\leq 1.0$ "

Table 2 Statistics of the vulnerability index of forest type distribution

\begin{tabular}{|c|c|c|c|c|c|c|}
\hline \multirow[t]{2}{*}{ Indicators and indices (forest type distribution) } & \multicolumn{2}{|l|}{ Sensitivity } & \multicolumn{2}{|c|}{ Adaptation capacity } & \multicolumn{2}{|c|}{ Vulnerability index } \\
\hline & Area $\left(\mathrm{km}^{2}\right)$ & $(\%)$ & Area $\left(\mathrm{km}^{2}\right)$ & $(\%)$ & Area $\left(\mathrm{km}^{2}\right)$ & $(\%)$ \\
\hline Very high & 114 & 0.17 & 11,660 & 16.91 & 544 & 0.79 \\
\hline High & 3235 & 4.69 & 47,747 & 69.25 & 18,850 & 27.34 \\
\hline Moderate & 16,649 & 24.15 & 9479 & 13.75 & 33,863 & 49.12 \\
\hline Low & 35,590 & 51.62 & 60 & 0.09 & 14,594 & 21.17 \\
\hline Very low & 13,358 & 19.37 & - & 0.00 & 1095 & 1.59 \\
\hline Total & 68,946 & 100.00 & 68,946 & 100.00 & 68,946 & 100.00 \\
\hline
\end{tabular}

Table 3 Statistics of the vulnerability index of NPP (net primary production)
Table 4 Statistics of the vulnerability index of SCS (soil carbon storage)

\begin{tabular}{|c|c|c|c|c|c|c|}
\hline \multirow[t]{2}{*}{ Indicators and indices (NPP) } & \multicolumn{2}{|l|}{ Sensitivity } & \multicolumn{2}{|c|}{ Adaptation capacity } & \multicolumn{2}{|c|}{ Vulnerability index } \\
\hline & Area $\left(\mathrm{km}^{2}\right)$ & $(\%)$ & Area $\left(\mathrm{km}^{2}\right)$ & $(\%)$ & Area $\left(\mathrm{km}^{2}\right)$ & $(\%)$ \\
\hline Very high & 17 & 0.02 & 6142 & 8.91 & 2 & 0.00 \\
\hline High & 819 & 1.19 & 44,049 & 63.89 & 180 & 0.26 \\
\hline Moderate & 3423 & 4.96 & 15,877 & 23.03 & 9472 & 13.74 \\
\hline Low & 13,383 & 19.41 & 2822 & 4.09 & 40,704 & 59.04 \\
\hline Very low & 51,304 & 74.41 & 57 & 0.08 & 18,588 & 26.96 \\
\hline Total & 68,946 & 100.00 & 68,946 & 100.00 & 68,946 & 100.00 \\
\hline
\end{tabular}

\begin{tabular}{|c|c|c|c|c|c|c|}
\hline \multirow[t]{2}{*}{ Indicators and indices (SCS) } & \multicolumn{2}{|l|}{ Sensitivity } & \multicolumn{2}{|c|}{ Adaptation capacity } & \multicolumn{2}{|c|}{ Vulnerability index } \\
\hline & Area $\left(\mathrm{km}^{2}\right)$ & $(\%)$ & Area $\left(\mathrm{km}^{2}\right)$ & $(\%)$ & Area $\left(\mathrm{km}^{2}\right)$ & $(\%)$ \\
\hline Very high & 31 & 0.04 & 326 & 0.47 & 3 & 0.00 \\
\hline High & 458 & 0.66 & 2490 & 3.61 & 9261 & 13.43 \\
\hline Moderate & 4363 & 6.33 & 5429 & 7.87 & 28,173 & 40.86 \\
\hline Low & 34,095 & 49.45 & 27,886 & 40.45 & 23,592 & 34.22 \\
\hline very low & 30,000 & 43.51 & 32,815 & 47.60 & 7917 & 11.48 \\
\hline Total & 68,946 & 100.00 & 68,946 & 100.00 & 68,946 & 100.00 \\
\hline
\end{tabular}


(Fig. 3b). Interestingly, other regions represented the opposite tendencies in sensitivity and adaptation capacity, and thereby compensated each other (and thus, yielded a lower vulnerability index for NPP) when compared to the west-central and eastern mountainous regions.

The vulnerability index was higher, on average, for SCS than for NPP (Fig. 5c). Yet, SCS was less susceptible than forest type distribution. Moderate to high vulnerability for SCS was predicted for the west-central and southern regions ( $>50 \%$ of South Korean forests), whereas a significant portion of forests $(>35 \%)$ were predicted to have low vulnerability to change in SCS over the eastern mountainous regions. Throughout South Korean forests, the MC1 model simulated loss of resilience in SCS from the 1970 s to the 2090s, except for the eastern mountains, where consistent increments of SCS resulted in a high sensitivity criterion.

Figure 4 shows the overall accumulated deviations of NPP and SCS from the long-term means in a fixed period (1970 to 2090s) of the MC1 simulations. The trend of NPP deviations suggests that South Korean forests might be able to retain the resilience (negative slope) on average, whereas the relatively lower adaptation capacity for SCS (positive slope) is expected from the 1970s to the 2090s.

\section{Temporal and spatial transitions of vulnerabilities for each sector}

Temporal and spatial transitions of the vulnerabilities to climate change were examined for forest type distribution, NPP, and SCS. We assessed the vulnerability indices for the three sub-periods using the same manner for the entire period as in "Vulnerability of forest type distribution and carbon-related functions (NPP and SCS)" section. The current condition represents from the 1970s to the 2010s, whereas the near future refers to the 2010s to the 2050s, and the distant future corresponds to the 2050s to the 2090s (Fig. 5). The vulnerability indices for each sector showed clear disparities in their temporal (current, near and distant future) and spatial (eastern mountains, southern inlands, west-central regions) patterns.

\section{Vulnerability index for forest type distribution}

South Korean forests were generally less vulnerable to current climatic conditions (1970-2010 s) in terms of forest type (Fig. 3a). Only a small portion of the southeastern inlands showed moderate vulnerability due to the expansion of warm temperate mixed forests. However, in the near future (2010-2050s), significant retreats of cool temperate and temperate forests were predicted. This could lead to an overall increase in vulnerability in the westcentral and southern coastal regions. The eastern mountains would remain relatively protected against forest type changes in the near future. Warm temperate and subtropical forests became stabilized in the southern regions and invaded northwards in the distant future (2050-2090s). Therefore, relatively vulnerable regions were mainly located in the west-central region with a higher vulnerability index compared to the other temporal periods and districts. Remaining as a habitat for cool temperate and temperate forests, the eastern mountains were less vulnerable in the distant future.

\section{Vulnerability index for NPP}

Unlike forest type and SCS, the lowest vulnerability index for NPP was obtained in current climatic conditions. Only a small region in the eastern mountains faced relatively high vulnerability. NPP vulnerability was of less concern with regard to the simulation period of 1970-2090s (Fig. 3b),
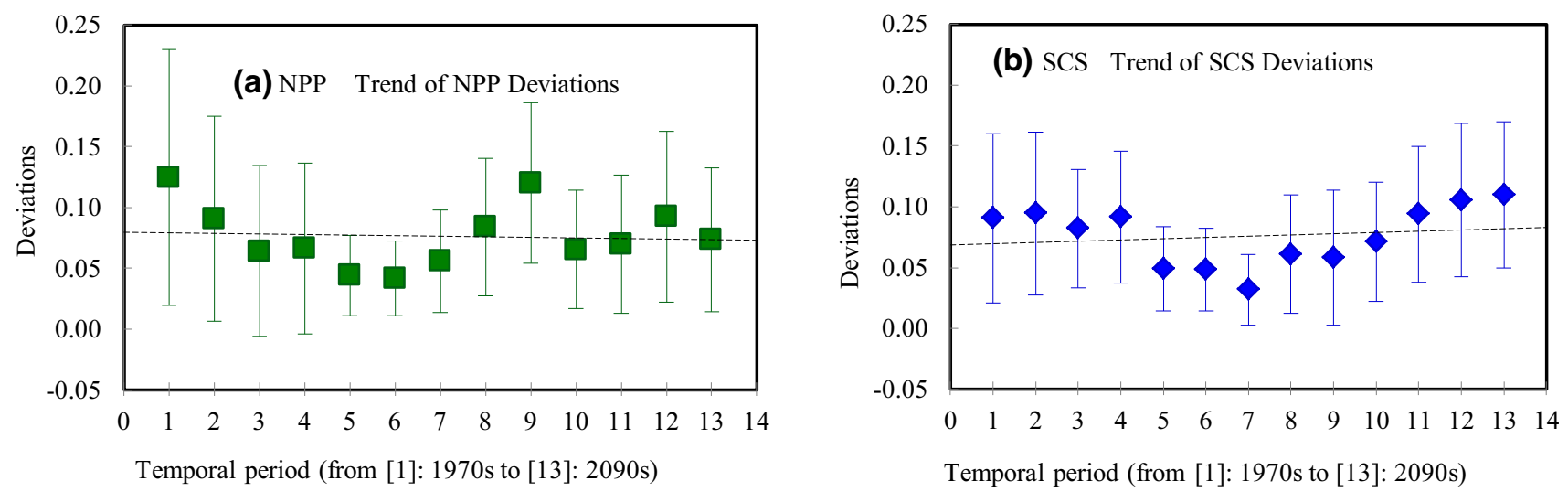

Fig. 4 Accumulated deviations and trend of deviations of a NPP and b SCS from the long-term (1970-2090s) MC1 simulations. Temporal periods (1-13) represent simulations from the 1970s to the 2090s under the A1B scenario of the IPCC 
Normalized vulnerability index for forest type distribution
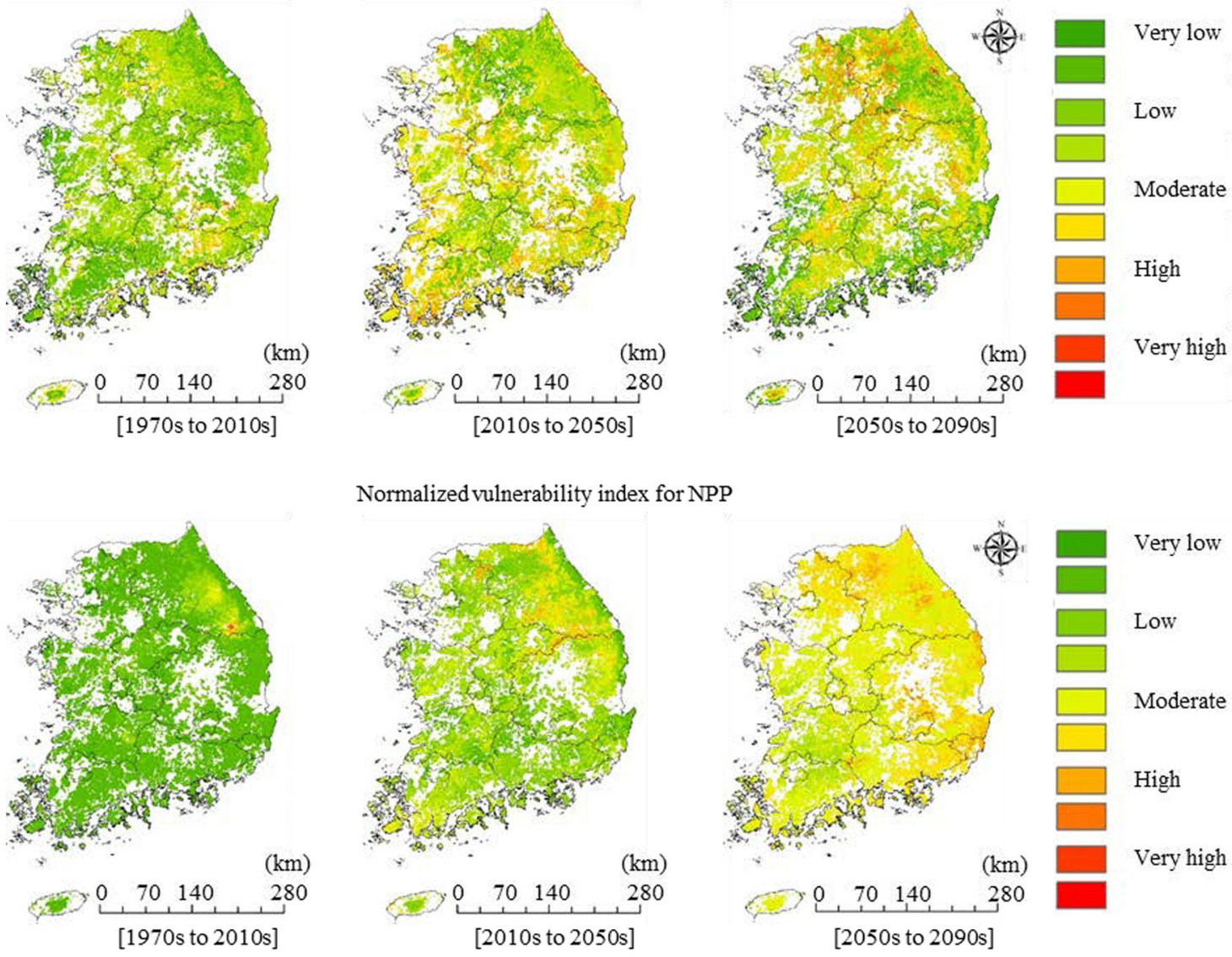

Normalized vulnerability index for NPP
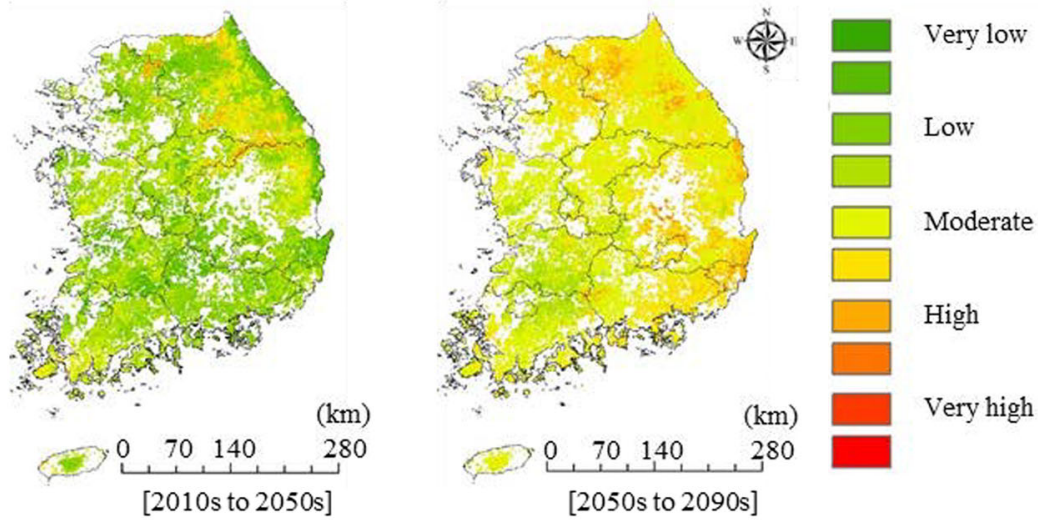

Normalized vulnerability index for SCS
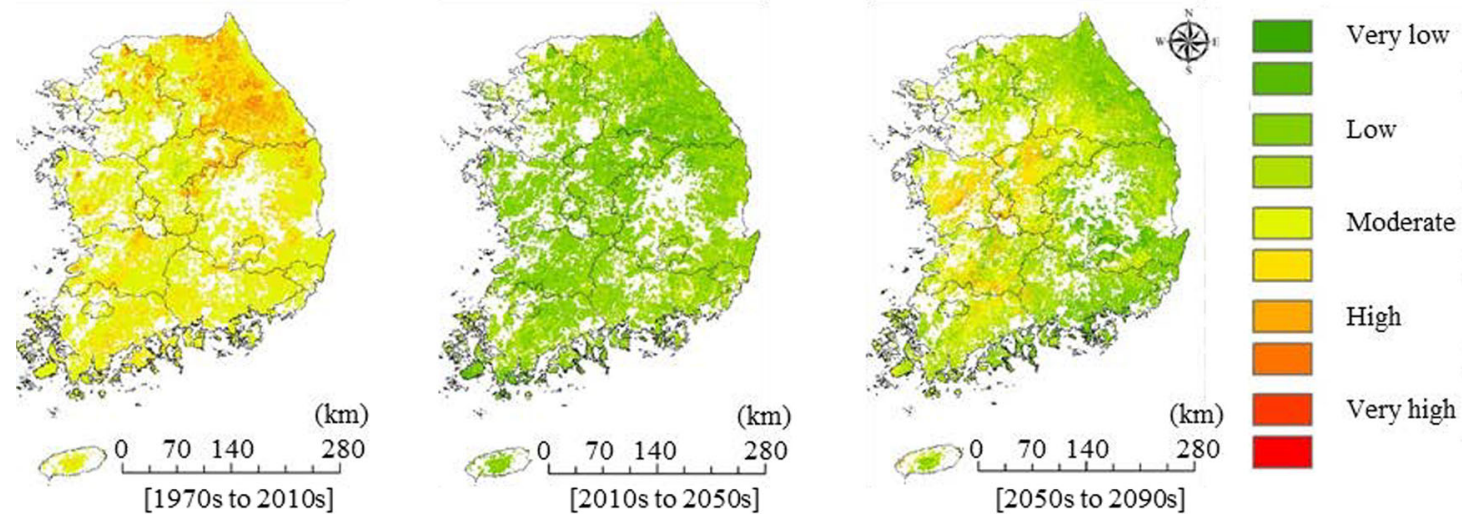

Fig. 5 Temporal and spatial transitions of climate change vulnerability indices for forest type distribution, NPP, and SCS. We assessed the vulnerabilities for three sub-periods using the same manner for the entire period. Current conditions represent from the 1970s to the

but our analysis using the sub-temporal periods showed increasing relative susceptibility to climate change in the near and distant future. In particular, NPP fluxes were scattered in highly vulnerable forests in the eastern mountain regions.
2010 s, near future refers to the 2010 s to the 2050 s, and distant future corresponds to the 2050s to the 2090s. The five classes in the maps represent " $0.0 \leq$ Very low $<0.2$ atial $t r \leq$ Low $<0.4$ ", " $0.4 \leq$ Moderate $<0.6$ ", " $0.6 \leq$ High $<0.8$ ", and " $0.8 \leq$ Very high $\leq 1.0$ "

\section{Vulnerability index for SCS}

SCS in was mostly susceptible to current climatic conditions. As in the MC simulations, the severe reduction of SCS in the eastern mountain regions might be related to the 
high vulnerability index. It was interesting that South Korean forests recovered their resilience for SCS in the near future. However, re-increments of vulnerability in the distant future were notable. We believe that this revived increasing trend (particularly in the west central regions) has significant influences, and thus might lead to the high vulnerability index for SCS based on the entire temporal period (Fig. 3c).

\section{A synoptic overview of vulnerabilities by administrative districts}

Our ultimate goal in this study was to produce a synoptic overview using the climate change impacts quantified above for the three sectors. Here, we suggest a framework that may grant a simple but integrated scientific background for policy-makers in South Korea. Instead of complicating earlier modeled values, our framework developed numerical indices for each sector and this enabled comparisons to be made by the administrative districts. As we spatially stratified and normalized the indices over the entirety of South Korean forests, no weighting processes were used for this framework.

Based on the geographic information system (GIS) zonal statistics technique, the mean vulnerability indices for each sector and for each administrative boundary (16 main districts) were calculated. Maximum and minimum values for each district were also explored in this framework. Our results for the vulnerability assessment using the entire simulation period (1970-2090 s) are summarized in a radar graph (Fig. 6).

NPP vulnerability, in general, was of least concern for policy-makers (except for Busan), whereas the highest priority sector (either forest types or SCS) varied by administrative district. For example, according to the synoptic overview, South Korean policy-makers are recommended to take adaptive actions primarily for the susceptible SCS in Dajeon and Chungnam. On the other hand, Daegu and Busan policy-makers could focus on protective measures for forest type changes rather than on NPP or SCS. The recommended adaptive actions for each discipline are discussed in "Conclusion" section.

Additional interpretations for this radar graph are twofold. First, we can apply this framework to the temporal and spatial transitions of the vulnerabilities of Fig. 7. SCS was the most vulnerable sector over the 16 administrative districts under current climatic conditions, and forest type distribution and NPP were of the greatest concern in the near and distant future, respectively (Fig. 7). This implies our framework may support short- to long-term decisionmaking processes. Second, the upper and lower vulnerability indices for each sector (95\% confidence level) in the radar graph indicate that large variations exist within a given administrative district. Thus, we recommend subsequent vulnerability assessments at a sub-province level prior to taking adaptive actions in each province.

\section{Discussion}

\section{Adaptive measures for each sector}

Because the autonomous adaptation capacity of forests would not be adequate to cope with the impacts of future climate change, management measures might be required to alleviate forest vulnerability. We believe that the above synoptic overview of our framework further benefits policy-makers if accompanied by a list of suggested adaptive actions.

\section{Adaptive actions for forest type distribution}

Policy-makers should first identify what to protect (historically-currently valued forest types) and where to protect based on both long-term monitoring and model-based assessments. Two options may be useful for the forest type sector (Scott and Lemieux 2005): (a) to exclude potentially invasive species (e.g., southern species in warm/subtropical forests) from the protected regions to maintain the current ecological representation; or (b) to re-introduce endangered species or make more natural resources (water or nutrients) available to compensate the worsening current habitat conditions.

\section{Adaptive actions for NPP and SCS}

The MC1 predicted, on average, an increasing trend of NPP and a decreasing trend of SCS for the entirety of South Korea. An abnormal change of NPP is likely to deplete soil nutrients (and in turn, have negative impacts on growth), or to allocate biomass to rapid turnover tissues (e.g., fine roots or foliage) rather than stem wood and coarse roots (Schlesinger and Lichter 2001). Forest management plans (e.g., thinning, fertilization, harvesting, and replanting) have been recommended to maintain the resilience of forest NPP fluxes and growth (Eriksson et al. 2007).

Reduction in SCS is related to soil respiration, a complex process that is affected by numerous factors (Jackson et al. 2000). Lal (2004) recommended several management practices in relation to SCS: (a) agroforestry might be a measure for improving SCS, (b) SCS would be protected from microbial processes (as recalcitrant $\mathrm{C}$ with long turnover time) if depth distribution of soil carbon is improved and if SCS is stabilized within micro-aggregates, and (c) soil biodiversity (i.e., earthworms, termites, and ants, etc.) has a positive impact on SCS. 


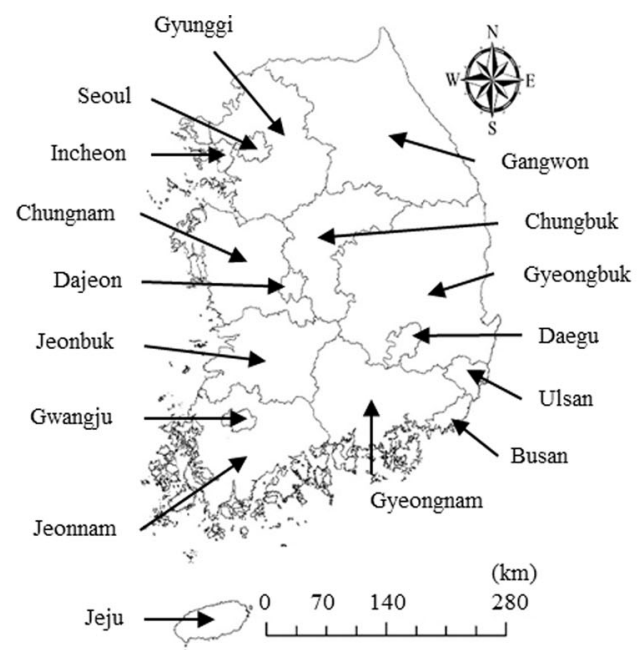

Fig. 6 A synoptic overview of climate change vulnerabilities in 16 administrative districts. The radar-shape chart shows the overall vulnerability (from the 1970s to the 2090s) for each administrative province. Solid lines represent the mean vulnerability index over each

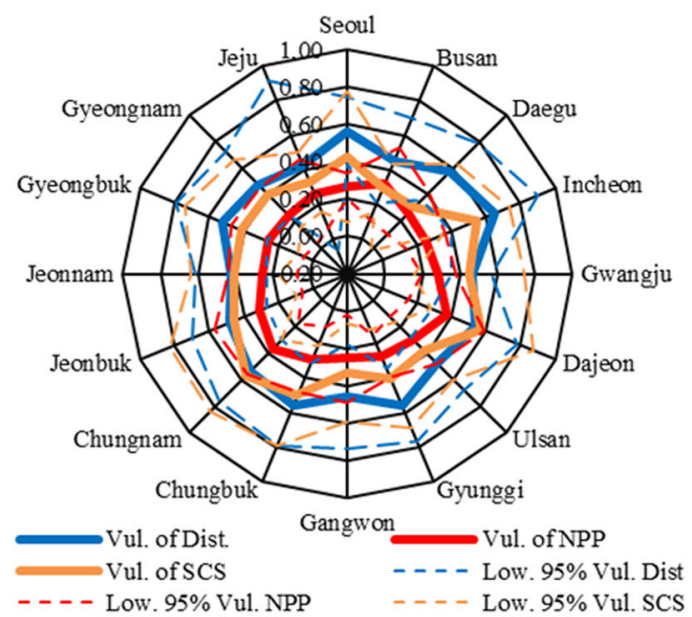

province. Upper and lower limits (95\% confidence level $=2$ standard deviations) in each province are given in dashed lines. Vul. vulnerability index, Dist. forest type distribution, Low lower limits, Up. upper limits

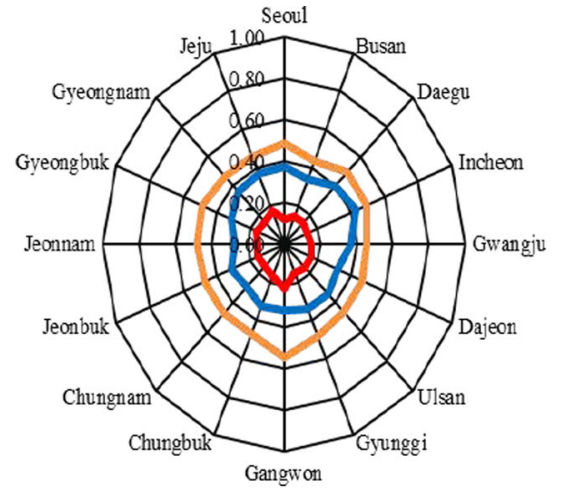

$\longrightarrow$ Vul. of Dist

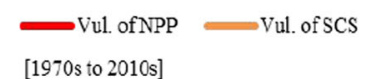

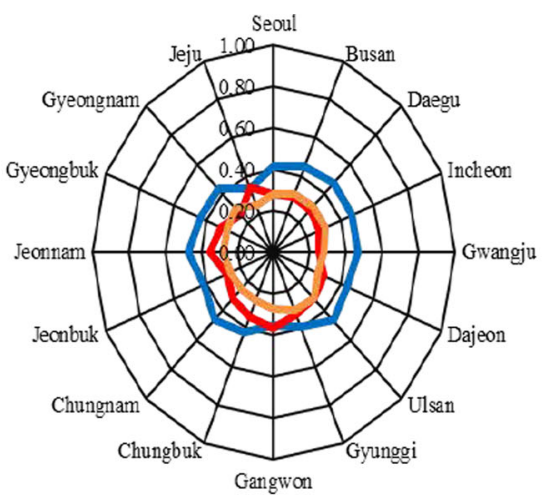

$\smile$ Vul. of Dist.

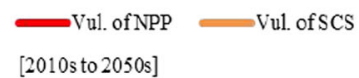

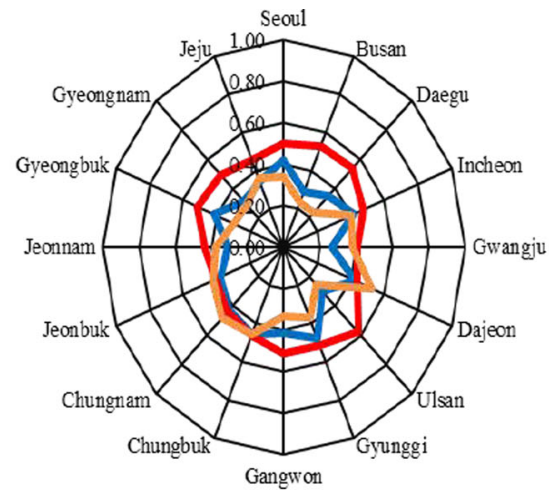

$\longrightarrow$ Vul. of Dist.

[2050s to 2090s]
Fig. 7 Synoptic overviews of climate change vulnerabilities in 16 administrative districts for three sub-periods. Radar-shape charts show the vulnerabilities for the current (1970-2010s), near future

\section{Limitations of our framework and subsequent research}

One of the main assumptions in this study is that three sectors (forest types, NPP and SCS) are treated as independent. The vulnerability indices for these sectors were combined into a synoptic overview. However, independence of sectors is obviously not valid in nature. For instance, forest types are strongly related to carbon-related functions (e.g., NPP; Bachelet et al. 2001). A radical alteration of forest types would influence carbon-related functions. SCS is often influenced by soil respiration and temperatures, but NPP is a main driver for SCS (Norby (2010-2050s) and distant future (2050-2090s) for each administrative province. Solid lines represent the mean vulnerability index of each province. Vul. vulnerability index, Dist. forest type distribution

et al. 2002; Yoo et al. 2013). This is one of challenges for our subsequent research. Although recent models account for both forest type and carbon dynamics (e.g., Ecosystem Demographic model (Moorcroft et al. 2001)), their PFTs are not sufficiently specified for South Korean forests at a local scale. Because we used model-based results for our vulnerability assessment, our results should be carefully interpreted in consideration of inherent uncertainties and errors in the individual models. For example, the HyTAG model does not address competition between species, agerelated stand replacement, and "lag time" (time delay) in retreat or regeneration of forests. The MC1 model also does not account for forest stand age, which is an important 
driver of carbon flux/storage (e.g., Shugart et al. 2010). In addition, neither HyTAG nor MC1 provide error terms in the simulations that could be essential for propagating uncertainties in our vulnerability assessments. A coupled model inter-comparison project (e.g., CMIP (Friedlingstein et al. 2006)) would be a useful candidate as a benchmark for vulnerability assessments in subsequent research. Once we present variations in multi-model results for each sector, the users of our framework (e.g., policy-makers) could selectively accept the suggested scientific backgrounds along with the propagated uncertainties derived from individual models.

In addition, our framework addressed only the autonomous adaptation capacity of forests, but did not consider the direct effect of human society (e.g., adaptive actions in Sect. 5.1). It would be interesting if we could combine both autonomous and heteronomous adaptive capacities regarding forest type distribution and carbon-related functions. Lastly, there are newly updated future climate scenarios of the IPCC (e.g., Representative Concentration Pathway; RCP 2.6/4.5/6/8.5; Van Vuuren et al. 2011). Additional research using these RCPs is recommended.

\section{Conclusion}

Vulnerability to climate change of forest type distribution, NPP, and SCS of South Korean forests was assessed using model simulations for South Korea and GIS-based spatial and temporal data. The HyTAG model simulated potential forest type distributions, and the MC1 model predicted forest carbon-related functions (NPP and SCS) from the 1970 s to the 2090s under the A1B scenario of the IPCC. Our results show that the overall vulnerability of forest type distribution was greater in the west-central regions and the southeastern inlands. The NPP-related vulnerability was relatively low, and highly vulnerable regions of SCS mainly spread from the west-central region to the southeast region. The estimated vulnerability indices varied depending on forest type, NPP, and SCS, the temporal period transitions (current, near and distant future), and three main districts (eastern mountains, southern inlands, west-central regions). Our framework produced a synoptic overview using the above quantified vulnerability indices. This may provide a simple yet integrated scientific background for policy-makers in South Korea to make priority decisions for adaptive measures in each administrative district.

Acknowledgments This project was funded by the Korea Ministry of Environment as "The Climate Change Correspondence R\&D Project (RE 201206045)" and "Climate Change Correspondence Program” (Project Number: 2014001310008).
Open Access This article is distributed under the terms of the Creative Commons Attribution 4.0 International License (http://crea tivecommons.org/licenses/by/4.0/), which permits unrestricted use, distribution, and reproduction in any medium, provided you give appropriate credit to the original author(s) and the source, provide a link to the Creative Commons license, and indicate if changes were made.

\section{References}

Arvai J, Bridge G, Dolsak N, Franzese R, Koontz T, Luginbuhl A, Robbins P, Richards K, Korfmacher KS, Sohngen B, Tansey J, Thompson A (2006) Adaptive management of the global climate problem: bridging the gap between climate research and climate policy. Clim Change 78(1):217-225

Bachelet D, Lenihan JM, Daly C, Neilson RP, Ojima DS, Parton WJ (2001) MC1: a dynamic vegetation model for estimating the distribution of vegetation and associated carbon, nutrients, and water. Technical documentation version 1.0. Oregon State University, Colorado State University. US Department of Agriculture, Forest Service, Pacific Northwest Research Station, pp 6-25

Byun J, Lee WK, Choi S, Oh SH, Yoo S, Kwon TS, Sung JH, Woo JW (2012) Vulnerability assessment for forest ecosystem to climate change based on spatio-temporal information. Korean $\mathbf{J}$ Remote Sens 28(1):159-171

Cha DH, Lee DK (2009) Reduction of systematic errors in regional climate simulations of the summer monsoon over East Asia and the western North Pacific by applying the spectral nudging technique. J Geophys Res-Atmos 114:D14108. doi:10.1029/ 2008JD011176

Choi S, Lee WK, Son Y, Yoo S, Lim JH (2010) Changes in the distribution of South Korean forest vegetation simulated using thermal gradient indices. Sci China Ser C-Life Sci 53(7):784-797

Choi S, Lee WK, Kwak DA, Lee S, Son Y, Choi H, Lim JH, Saborowski J (2011a) Predicting forest type changes in future climate using hydrological and thermal indices in South Korea. Clim Res 49(3):229-245

Choi S, Lee WK, Kwak H, Kim SR, Yoo S, Choi HA, Park SM, Lim JH (2011b) Vulnerability assessment of forest ecosystem to climate change in Korea using MC1 model. J For Plan Jpn 16:149-161

Eriksson E, Gillespie AR, Gustavsson L, Langvall O, Olsson M, Sathre R, Stendahl J (2007) Integrated carbon analysis of forest management practices and wood substitution. Can J For Res 37(3):671-681

Evrendilek F, Berberoglu S, Gulbeyaz O, Ertekin C (2007) Modeling potential distribution and carbon dynamics of natural terrestrial ecosystems: a case study of Turkey. Sensors 7(10):2273-2296

Friedlingstein P, Cox P, Betts R, Bopp L, BlohW Von, Brovkin V, Cadule P, Doney S, Eby M, Fung I, Bala G, John J, Jones C, Joos F, Kato T, Kawamiya M, Knorr W, Lindsay K, Matthews HD, Raddatz T, Rayner P, Reick C, Roeckner E, Schnitzler KG, Schnur R, Strassmann K, Weaver AJ, Yoshikawa C, Zeng N (2006) Climate-carbon cycle feedback analysis: results from the C4MIP model intercomparison. J Clim 19(14):3337-3353

Füssel HM, Klein RJ (2006) Climate change vulnerability assessments: an evolution of conceptual thinking. Clim Change 75(3):301-329

Houghton RA (2007) Balancing the global carbon budget. Annu Rev Earth Planet Sci 35:313-347

Jackson RB, Schenk HJ, Jobbagy EG, Canadell J, ColelloGD Colello GD, Dickinson RE, Field CB, Friedlingstein P, Heimann M, 
Hibbard K, Kicklighter DW, Kleidon A, Neilson RP, Parton WJ, Sala OE, Sykes MT (2000) Belowground consequences of vegetation change and their treatment in models. Ecol Appl 10(2):470-483

Joshi PK, Rawat A, Narula S, Sinha V (2012) Assessing impact of climate change on forest cover type shifts in Western Himalayan Eco-region. J For Res 23(1):75-80

Kim JW, Lee D-K (2006) A study on the vulnerability assessment of forest vegetation using regional climate model. Korea Soc For Environ Restor Reveg Technol 9:32-40

Kim SN, Lee WK, Son Y, Cho Y, Lee MS (2009) Applicability of climate change impact assessment models to Korean forest. J Korean For Soc (in Korean) 98(1):33-48

Kira T (1948) On the altitudinal arrangement of climatic zones in Japan. Kanti-Nogaku 2:143-173

Kirschbaum MU (1995) The temperature dependence of soil organic matter decomposition, and the effect of global warming on soil organic C storage. Soil Biol Biochem 27(6):753-760

Kong WS (2005) Selection of vulnerable criterion plants by global warming. Korean J Atmos Sci (in Korean) 41(2-1):263-273

Korea Forest Service (2011) Statistical yearbook of forestry. Korea Forest Service, Seoul, pp 1-484

Lal R (2004) Soil carbon sequestration to mitigate climate change. Geoderma 123(1):1-22

Lee MA, Lee WK, Song CC, Lee JH, Choi HA, Kim TM (2007a) Spatio-temporal change prediction and variability of temperature and precipitation. J GIS Assoc Korea (in Korean) 15(3):267-278

Lee MA, Lee WK, Son Y, Cho Y, Song CC, Kim TM, Yu L, Tao B (2007b). Sensitivity and adaptability of vegetation and soil carbon storage to climate change with CEVSA model in Korea, proceeding of A3 foresight program, p 24

Lee WK, Yoo S, Byun JG, Lee SC, Raesun J (2010) Impact assessment on ecosystem of the Korean Peninsula: vulnerability assessment to climate change scenarios (in Korean). South Korea: Korea Environment Institute pp 15-124

Lee S, Choi S, Lee W-K, Park T, Oh S, Kim SN (2011) Vulnerability assessment of forest distribution by the climate change scenarios. J Korean For Soc 100(2):256-265

Lenihan JM, Bachelet D, Neilson RP, Drapek R (2008) Response of vegetation distribution, ecosystem productivity, and fire to climate change scenarios for California. Clim Change 87(1):215-230

Lindner M, Maroschek M, Netherer S, Kremer A, Barbati A, Gonzalo JG, Seidl R, Delzon S, Corona P, Kolström M, Lexer MJ, Marchetti M (2010) Climate change impacts, adaptive capacity, and vulnerability of European forest ecosystems. For Ecol Manag 259(4):698-709

McCarthy JJ (2001) Climate change 2001: impacts, adaptation, and vulnerability: contribution of working group II to the third assessment report of the intergovernmental panel on climate change. Cambridge University Press, Cambridge, pp 235-342

Min SK, Legutke S, Hense A, Cubasch U, Kwon WT, Oh JH, Schlese $\mathrm{U}$ (2006) East Asian climate change in the 21st century as simulated by the coupled climate model ECHO-G under IPCC SRES scenarios. J Meteorol Soc Jpn 84(1):1-26

Moorcroft P, Hurtt G, Pacala SW (2001) A method for scaling vegetation dynamics: the ecosystem demography model (ED). Ecol Monogr 71(4):557-586

Myneni RB, Keeling C, Tucker C, Asrar G, Nemani R (1997) Increased plant growth in the northern high latitudes from 1981 to 1991 . Nature $386: 698-702$

Nakicenovic N, Alcamo J, Davis G, de Vries B, Fenhann J, Gaffin S, Gregory K, Griibler A, Jung TY, Kram T, Lebre E, Rovere L, Michaelis L, Mori S, Morita T, Smith S, Swart R, Rooijen SV, Victor N, Dadi Z (2000) Emission scenarios. A special report of working group III of the Intergovernmental panel on climate change. Cambridge University Press, Cambridge, pp 1-595
Neilson RP (1995) A model for predicting continental-scale vegetation distribution and water balance. Ecol Appl 5(2):362-385

Norby RJ, Hanson PJ, O'Neill EG, Tschaplinski TJ, Weltzin JF, Hansen RA, Cheng WX, Wullschleger SD, Gullschleger CA, Edwards NT, Johnson DW (2002) Net primary productivity of a $\mathrm{CO} 2$-enriched deciduous forest and the implications for carbon storage. Ecol Appl 12(5):1261-1266

Parton W (1996) The century model. Evaluation of soil organic matter models. Springer, New York, pp 283-291

Pearson RG (2006) Climate change and the migration capacity of species. Trends Ecol Evol 21(3):111-113

Pearson RG, Dawson TP (2003) Predicting the impacts of climate change on the distribution of species: are bioclimate envelope models useful. Glob Ecol Biogeogr 12(5):361-371

Prentice IC, Cramer W, Harrison SP, Leemans R, Monserud RA, Solomon AM (1992) Special paper: a global biome model based on plant physiology and dominance, soil properties and climate. J Biogeogr 19:117-134

SAS Institute Inc. (2009) SAS 9.2 help and documentation. SAS Institute, Cary

Schlesinger WH, Lichter J (2001) Limited carbon storage in soil and litter of experimental forest plots under increased atmospheric $\mathrm{CO}_{2}$. Nature 411(6836):466-469

Schulze E-D, Wirth C, Heimann M (2000) Managing forests after Kyoto. Science (Washington) 289(5487):2058-2059

Scott D, Lemieux C (2005) Climate change and protected area policy and planning in Canada. For Chronicle 81(5):696-703

Shugart HH, Saatchi S, Hall FG (2010) Importance of structure and its measurement in quantifying function of forest ecosystems. J Geophys Res-Biogeosci. doi:10.1029/2009JG000993

Smith CD (2008) The relationship between monthly precipitation and elevation in the Alberta foothills during the foothills orographic precipitation experiment. Cold region atmospheric and hydrologic studies the mackenzie GEWEX experience. Springer, New York, pp 167-185

Thornthwaite CW (1948) An approach toward a rational classification of climate. Geogr Rev 38(1):55-94

Van Vuuren DP, Edmonds J, Kainuma M, Riahi K, Thomson A, Hibbard K, Hurtt GC, Kram T, Krey V, Lamarque JF, Masui T, Meinshausen M, Nakicenovic N, Smith SJ, Rose SK (2011) The representative concentration pathways: an overview. Clim Change 109:5-31

Wang M, Li QR, Xiao DM, Dong BL (2004) Effects of soil temperature and soil water content on soil respiration in three forest types in Changbai Mountain. J For Res 15(2):113-118

Wang HM, Saigusa N, Zu YG, Wang WJ, Yamamoto S, Kondo H (2008) Carbon fluxes and their response to environmental variables in a Dahurian larch forest ecosystem in northeast China. J For Res 19(1):1-10

Watson RT, Albritton DL (2001) Climate change 2001: synthesis report: third assessment report of the intergovernmental panel on climate change. Cambridge University Press, Cambridge, pp 1-284

Yoo SJ, Kwak DA, Cui GS, Lee WK, Kwak HB, Ito A, Son YH, Jeon SW (2013) Estimation of ecosystem carbon budget in South Korea between 1999 and 2008. Ecol Res 28(6):1045-1059

Yu L, Cao M, Li K (2005) An overview of assessment of ecosystem vulnerability to climate change. Prog Geogr 24(1):61-67

Yu L, Cao M, Li K (2006) Climate-induced changes in the vegetation pattern of China in the 21st century. Ecol Res 21(6):912-919

Yu L, Cao MK, Tao B, Li KR, Dong WJ, Liu HB, Liu CY (2008) Quantitative assessment of the vulnerability of terrestrial ecosystems of china to climate change based on potential vegetation. Chin J Plant Ecol 32(3):521-530

Yun JI, Choi JY, Ahn JH (2001) Seasonal trend of elevation effect on daily air temperature in Korea. Korea J Agric Meteorol 3(2):96-104 
Zhang HL, Liu GH, Feng XF (2011) A process model for simulating net primary productivity (NPP) based on the interaction of water-heat process and nitrogen: a case study in Lantsang valley. J For Res 22(1):93-97
Zhu WQ, Pan YZ, Liu X, Wang AL (2006) Spatio-temporal distribution of net primary productivity along the Northeast China Transect and its response to climatic change. J For Res 17(2):93-98 